\title{
Trends in Hospitalisation for Human Immunodeficiency Virus in a Tertiary Hospital in Dar es Salaam, Tanzania: A Case study
}

\author{
Grace A Shayo a, Tumaini Nagua, Lilian Mselea, Patricia Munseria, Columba Mbekenga ${ }^{a}$ \\ Steven Kibusia, Kisali Pallangyo a, Ferdinand Mugusia \\ Muhimbili University of Health and Allied Sciences School of Medicine, Dar es Salaam, United Republic of Tanzania \\ Correspondence to Grace A Shayo (mundibilinga@yahoo.com)
}

\begin{abstract}
Background: Reports on systematic evaluation of the impact of antiretroviral therapy(ART) on patients' hospitalisation in Sub Saharan Africa (SSA) and Tanzania in particular are scarce. We aimed at documenting the trends of hospital admissions at Muhimbili National Hospital (MNH) following scale up of free access to ART in Tanzania.

Methods: Records for all admissions at MNH from June 2005 to June 2015 were reviewed. We extracted data from Hospital Information Management System as well as from patients' charts. Data extracted included diagnosis at discharge, reason for admission and thereafter assessed admission trends over the decade. We summarised the data as frequency and percentages. We compared proportions using Chi squared test, $\mathrm{P}<0.05$ was deemed significant.

Results: Overall there were 209,101 admissions during the study period (June 2005 to June 2015) and 7864/209,101 (3.8\%) were due to HIV infection. Whereas 598/4,519 (13.2\%) of all admissions in 2005 were due to HIV, only 345/13,119 (2.6\%) of admissions in 2015 were HIV-related; showing a significant drop over time $(P$ value for trend < .001$)$. Generally, females 3887/6679 (58.2\%) were more likely to be admitted than males (41.8\%). Median CD4 count for admitted HIV patients was 143 cells/ $\mu$ l. Majority of admissions occured in the medical wards $3643 / 5310$ (68.6\%). Discharge diagnoses were Tuberculosis 1396/6482 (21.5\%), anaemias 1016/6482 (15.6\%), malignancies 789/6482(12.2\%), CNS infections 541/6482 (8.3\%) and chronic kidney disease 308/6482 (4.8\%). Three leading AIDS defining malignancies among hospitalised patients included Kaposi's sarcoma 380/789 (48.2\%), carcinoma of the cervix 77/789 (9.8\%), and Non-Hodgkin's lymphoma 44/789 (5.6\%).

Conclusion: Despite drastic drop of HIV related admissions at Muhimbili National Hospital over the years, the infection remains a problem of the adults, largely females suffering from medical conditions and presenting with severe immunosuppression. Tuberculosis remained the most common opportunistic infection among hospitalized HIV infected patients. Anaemia and cancers became more important causes of admission than was diarrhoea which had been the most common among HIV infected patients in pre- ART era.
\end{abstract}

\section{BACKGROUND}

A the end of 2018, an estimated total of 75 million people A had been infected with Human Immunodeficiency Virus (HIV) and about 32 million people had died of HIV globally since the beginning of the epidemic in 1980. Globally, 37.9 million [32.7 to 44.0 million] people were living with HIV at the end of 2018. The WHO African region remains most severely affected accounting for two-thirds of the people living with HIV worldwide. In Africa, it is estimated that 1 in every 25 adults (3.9\%) is living with $\mathrm{HIV}^{1}$. Adolescent girls and young women aged 15-24 years have up to eight fold higher rates of HIV infection compared to their male peers and do acquire HIV infection 5-7 years before men ${ }^{2}$.

Diseases related to HIV infections were first reported in Tanzania from Kagera region in $1983^{3}$. By the end of 1986 cases of acquired immunodeficiency syndrome (AIDS) had been reported from all regions of Tanzania mainland. Parallel to an explosion of hospital admission of patients with full blown AIDS, patients with tuberculosis increased more than three folds. Unprecedented number of patients with other HIV related clinical conditions including Kaposi's sarcoma were also hospitalized in increasing numbers beginning the early 1980 's ${ }^{3}$.
Cases of AIDS were first reported at the then Muhimbili Medical Centre (now Muhimbili National Hospital), Dar es Salaam in 1984. Prevalence studies done beginning 1986 among medical admissions, pregnant women, and blood donors in Dar es Salaam showed that HIV infection was wide spread in the general population ${ }^{4}$.In early 1990's the prevalence of HIV among malnourished children was $25 \%$ compared to $1.5 \%$ in non-malnourished children ${ }^{5}$.HIV prevalence among pregnant women in 1984 was $3.2 \%$, reached a peak of $16 \%$ in $1989^{4}$ and then steadily declined thereafter, reported to be $3.3 \%$ by $2008^{6}$.

A high HIV seroprevalence and increased HIV-associated mortality were reported among patients with deep bacterial infections in the medical wards of Muhimbilit. A study involving 517 patients hospitalized in the medical wards with fever during February to April 1995 found that $55 \%$ of patients tested positive for $\mathrm{HIV}-1^{8}$ while $10.5 \%$ of surgical admissions in the same hospital from 2001 to 2002 were HIV infected 9 . A total of $118 / 145(81 \%)$ of surgical patients who confirmed to have blood stream infection were HIV infected ${ }^{7}$. The prevalence of HIV infection among patients hospitalised in the same hospital with pulmonary tuberculosis and/or extra-pulmonary tuberculosis during the 1990 s ranged from $33 \%$ to $50 \%{ }^{10-12}$. 
In late 1990s patients who presented with pyomyositis significantly presented with higher rate of HIV seropositivity $(62 \%)$ than were non-patient controls $(12 \%){ }^{7}$

In the 1990s free ART were not provided to a large part of Sub Saharan Africa (SSA) including Tanzania due to high cost of the antiretroviral drugs and lack of adequate laboratory capacities. Beginning 1996 combination therapies with three antiretroviral drugs were found to be more effective in lowering HIV viral load thus became standard of care for patients with HIV disease including AIDS in the industrialised countries. ${ }^{13,14}$ In early 2000 s physicians in Tanzania prescribed first line ART drugs in different combinations including dual therapy with zidovudine and lamivudine or triple therapy with Zidovudine, Nevirapine and Didanosine or Zidovudine, Nevirapine and Stavudine. It was not until 2005 that HIV treatment in Tanzania was standardized to 3 drugcombinations after the release of the first HIV guideline. The use of 3 drug combinations resulted into decreased hospitalisation and mortality rates with resultant increased life expectancy in different countries. ${ }^{15-17}$ Moreover, during the ART era, there has been a shift of causes of deaths from AIDS defining to non AIDS defining illnesses. ${ }^{18,19}$

In 2004 Tanzanian government launched a countrywide provision of ART to AIDS patients, commencing with a pilot clinic at Muhimbili National Hospital (MNH). National data for HIV prevalence among adults aged between 15 years and 49years gradually fell from $7 \%$ to $5.1 \%$ in $2003 / 4$ and $2011 / 12$ respectively. ${ }^{20,21}$ The 2016 National HIV survey found a National prevalence of HIV at $5.0 \%$, a similar figure as that of $2011 / 12^{22}$. With increased access to ART the average number of personal admissions due to HIV in various parts of the world fell by $39 \%$ early in 2000 and the overall number of hospital admissions due to HIV fell by about $10 \%$ to $65 \%$. This study therefore intended to document the trends of hospital admissions at MNH following free access and wide scale up of ART services in Tanzania.

\section{METHODS}

\section{Study Design, Site and Data Sources}

This hospital based cross sectional descriptive study aimed at describing trends in admission rates and reasons for admission over time following free ART access in November 2004. Hospital based data was collected at Muhimbili National Hospital (MNH), the largest tertiary hospital in the country and a university teaching hospital situated in the city of Dar es Salaam. $\mathrm{MNH}$ is a 1,500 bed facility, attending 1,000 to 1,200 outpatients weekly, and admitting 1,000 to 1,200 inpatients per week. It receives referral cases predominantly from within the city of Dar es Salaam and from all over the country. Figure 1 shows the location of Dar es Salaam city and its districts within Tanzania. We used electronic hospital information system and patients' paper files as source of the collected information on hospital admissions and the reasons for admission respectively.

\section{Data Collection Procedures}

Since electronic data was available from June 2005, we collected data on hospital admissions from June 2005 to June 2015. Information on date and number of admissions was extracted from the electronic records. We reviewed patients' paper files to collect information on causes of admissions and discharge diagnoses. Each admission was treated as a separate entity and analysed as such.

For this study, we included everyone who was admitted in the hospital in the specified time frame and we had no exclusion criteria. We obtained file registration numbers of all admitted HIV infected patients and thereafter retrieved the respective files from the records department. The investigators reviewed each of the patients' files. Clinical record forms were used to record the extracted data from hospital records. The information collected included socio-demographic data, HIV status, WHO HIV staging, CD4 cell counts, and status of antiretroviral therapy use, discharge diagnosis, duration of hospital stay and admission outcome (discharge or death). HIV status was ascertained by looking at the case notes. Some patients were already known to be HIV infected at the time of admission while some were tested and diagnosed with HIV infection during an index admission.

\section{Statistical Analysis}

Absolute numbers of admissions due to HIV over the study period are presented graphically to show the general admission trends over time. Proportions of HIV admissions overtime were calculated by dividing the total number of admissions due to HIV per year by the total number of hospital admissions in that particular year. We used STATA 12.0 statistical package (StataCorp, Texas U.S.A) to analyse the data, and Chi Square statistics test $\left(\chi^{2}\right)$ was performed to compare proportion of admissions due to HIV over time. $P<.05$ was considered significant.Causes of admissions are presented as absolute numbers as well as proportions

\section{Ethical Approval and Consent to Participate}

The study obtained ethical clearance from the Muhimbili University of Health and Allied Sciences (MUHAS) Institutional Review Board, reference number

MU/DRP/AEC/Vol.XVIII/139. The MNH management authorized unrestricted access to hospital records to extract required information for this study. The clinical request form (CRF) only included hospital registration numbers and patient's initials and not names. CRFs were kept locked in filing cabinets and made accessible to authorized personnel only.

\section{RESULTS}

In the span of 10 years, there were a total of 7,864 (3.8\%) admissions due to HIV out of 209,101 total hospital admissions. Absolute numbers of admissions in the hospital over the years were as shown in Figure 2. Admissions due to HIV dropped drastically from $13.2 \%(598 / 4519)$ in 2005 to $2.6 \%(345 / 13,119)$ in 2015 (See Table 1) [Chi square $=1748.473: P<.001$ ]

Comparison of hospital base (MNH) and general HIV prevalence in the city of Dar es Salaam is depicted in Figure 3. Decline of HIV prevalence was observed in both hospital and city surveys.

Out of 7864 HIV-related admissions, we managed to find 6874 $(87.4 \%)$ patients'files, from which data was extracted. Females constituted $3887 / 6874(58.2 \%)$ of the total HIV related admissions. Of the 6874 admissions only 5310 had recorded ward of admission. Majority of HIV related admissions were commonly found in medical wards $3643 / 5310$ (68.6\%). Other wards where HIV patients were admitted included surgical $795 / 5310$ (15.0\%),paediatric 531/5310(10.0\%), gynaecology $290 / 5310$ $(5.5 \%), 19 / 5310(0.4 \%)$ emergency medicine/ICU, 21/5310 $(0.4 \%)$ obstetrics and $11 / 5310(0.2 \%)$ psychiatry.Of the HIV related admissions, majority were on ART $(61.6 \%)$ and adults $(87.6 \%)$ aged $\geq 18$ years (See Table 2 ). Median CD4 cell counts (IQR) was 143 cells/ $\mu$ l(ranging from 48 cells $/ \mu 1$ to 320 cells $/ \mu 1$ ) whilst median (IQR) hospital stay was 7 days (ranging from 3 to 14days) (Not shown in the Table). 


\begin{tabular}{|c|c|c|c|}
\hline \multicolumn{4}{|c|}{$\begin{array}{l}\text { TABLE 1: Proportion of HIV-related admissions from } \\
\text { June } 2005 \text { to June } 2015\end{array}$} \\
\hline \multirow[t]{2}{*}{ Year } & \multirow{2}{*}{$\begin{array}{l}\text { Total Hospital } \\
\text { admissions }\end{array}$} & \multicolumn{2}{|c|}{ HIV-infected } \\
\hline & & Number & Percentage \\
\hline 2005 & 4,519 & 598 & 13.2 \\
\hline 2006 & 9,463 & 775 & 8.2 \\
\hline 2007 & 6,238 & 723 & 11.6 \\
\hline 2008 & 25,201 & 1611 & 6.4 \\
\hline 2009 & 28,734 & 736 & 2.6 \\
\hline 2010 & 26,988 & 587 & 2.2 \\
\hline 2011 & 26,774 & 561 & 2.1 \\
\hline 2012 & 21,578 & 703 & 3.3 \\
\hline 2013 & 18,742 & 369 & 2.0 \\
\hline 2014 & 27,745 & 856 & 3.1 \\
\hline 2015 & 13,119 & 345 & 2.6 \\
\hline TOTAL & 209,101 & 7,864 & 3.8 \\
\hline
\end{tabular}

\section{FIGURE 1: Location of Dar es Salaam City and lts Dis-} tricts within Tanzania

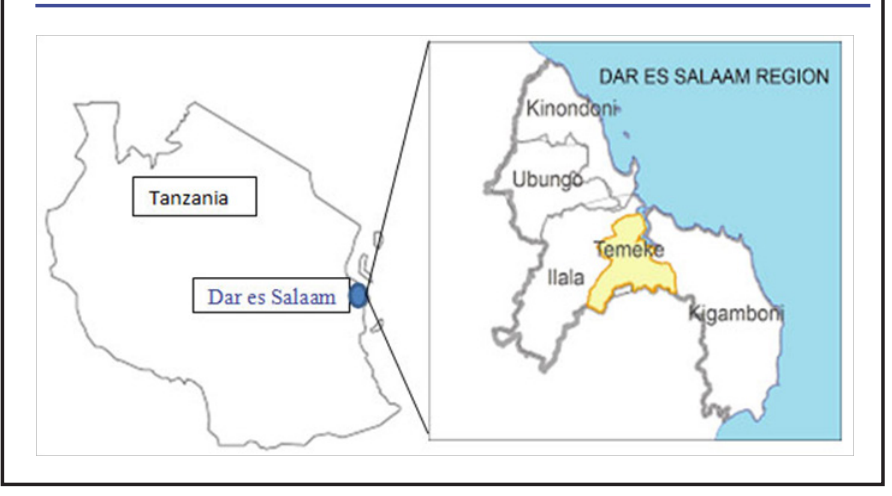

Out of 6874 reviewed patient's files, only 6482(94.3\%) had documented discharge diagnoses. The leading diagnoses were tuberculosis $1396 / 6482(21.5 \%)$, followed by anaemia $1016 / 6482$ (15.6\%), malignancies 789/6482 (12.2\%), central nervous system (CNS) infections 541/6482 (8.3\%), chronic kidney disease $308 / 6482$ (4.8\%), while cardiovascular diseases and diarrhoea each accounted 3.6\% (235/6482 and 231/6482 respectively). Chest infections other than tuberculosis were seen in $218 / 6482$ (3.4\%) while other forms of infections were seen in 206/6482 $(3.2 \%)$ of the total admissions. (See Table 3 )

\section{DISCUSSION}

The trend of HIV admissions at Muhimbili National Hospital showed a drastic drop from year 2005 to 2009 then plateaued to year 2015. The drop in number of patient admissions can be largely attributable to ART use and a decrease in HIV prevalence in the general population. However, the drop might as well be due to the fact that other public and private facilities are now more willing to hospitalize people with HIV disease. The present analysis has shown that there had been a surge of admissions among HIV negative individuals between years 2007 and 2014 probably due to more admissions of patients with non-communicable diseases owing to full operationalised cardiac building and renal services in the hospital which were not there before. Furthermore, the hospital bed capacity has expanded owing to existence of the new Paediatric block and the release of 2 wards from Muhimbili Orthopaedic Institute to Muhimbili National hospital. This surge can also partly be explained by the growth of the city's population which has almost doubled from the 2,487,288 people in 2002 to $4,364,541$ population in 2012 . It is estimated that there were $5,166,570$ million people in Dar es Salaam in 2015. ${ }^{25,26}$

We have had an increase in Non-Communicable Diseases (NCDs) like diabetes mellitus, hypertension and chronic kidney disease due to an increase in aging population. Generally, national HIV surveys had shown a decrease in HIV prevalence in Tanzania from $7.2 \%$ in $2004{ }^{20}$ to $5.1 \%$ in $2012 .^{21}$ This drop of prevalence has been reported in neighbouring countries as well as in most of Sub-Saharan countries. ${ }^{2,27,28}$ In Kenya HIV prevalence dropped from $7.2 \%$ in 2007 to $5.6 \%$ in $2012^{28}$ whilst in Uganda HIV prevalence dropped from $7.8 \%$ at the first survey round $1989 / 1990{ }^{29}$ to $6.2 \%$ in $2017 .{ }^{27} \mathrm{All}$ these findings are consistent with the findings of the present study.

Admissions from female patients were predominant, so were medical admissions and adult admissions. Predominance of female and adult admissions is attributable to higher rates of HIV infection among females than males and among adults than children in Tanzania. ${ }^{21}$ The median CD4 count was low indicating that HIV hospital admissions were predominantly among those with severe immunosuppression. The causes of admissions among HIV infected patients were largely tuberculosis, anaemia and cancers in that order, collectively constituting $49.3 \%$ of all admissions. Since the advent of HIV infection tuberculosis has remained the number one cause of morbidity and mortality among HIV infected patients. ${ }^{30,31}$ Tuberculosis has also remained the major cause of admission in Kenya.

In the present study, diarrhoea ranked the $7^{\text {th }}$ as the cause of admissions. This is a change of pattern from the situation in the pre-ART era when chronic diarrhoea used to be one of the most common complaints among HIV infected patients. Opportunistic infections' (OIs) pattern in the pre-ART era in Uganda showed that diarrhoea $<1$ month $(30.6 \%)$ was the second common OI after oral candidiasis $(34.6 \%)$ followed by geohelminths (26.5\%), M.tuberculosis $(17.7 \%)$, malaria $(15.1 \%)$ and bacterial pneumonia (11.2\%). In the Ugandan case, ART was able to change the pattern to geohelminths (32.4\%), diarrhoea $<1$ month $(25.6 \%)$, M.tuberculosis $(18.2 \%)$ and oral candida $(18.1 \%)$. $^{33}$

Among cancer admissions, Kaposi's sarcoma (KS) was the most common cause of admissions. Kaposi's sarcoma has been reported to have declined in other parts of the world. In Europe and U.S.A the rates of KS have declined by $30 \%$ to $50 \%$ since the introduction of ART. ${ }^{34}$ Despite Tanzania's achievement of the 2015 millennium goal number $6 \mathrm{c}$ of reducing $50 \%$ of TB prevalence and deaths from the 1990 values in the year 2013,35 tuberculosis remained the leading cause of admissions among HIV infected patients. In the present study TB was the number one cause of admission. It has been found that the rate of HIV-TB co-infection depends on the rate of HIV infection in the community. ${ }^{36}$ This fact explains why TB is still rampant, even after a drop of HIV prevalence in Tanzania. TB was the most common opportunistic infection in a study in India ${ }^{37}$ and the third common opportunistic infection in Ethiopia. ${ }^{38}$

Anaemia was the second most common cause of admission, 
TABLE 2: Characteristics of HIV Infected Patients Hospitalised in Muhimbili National Hospital From June 2005 To June $2015, \mathrm{~N}=6874$

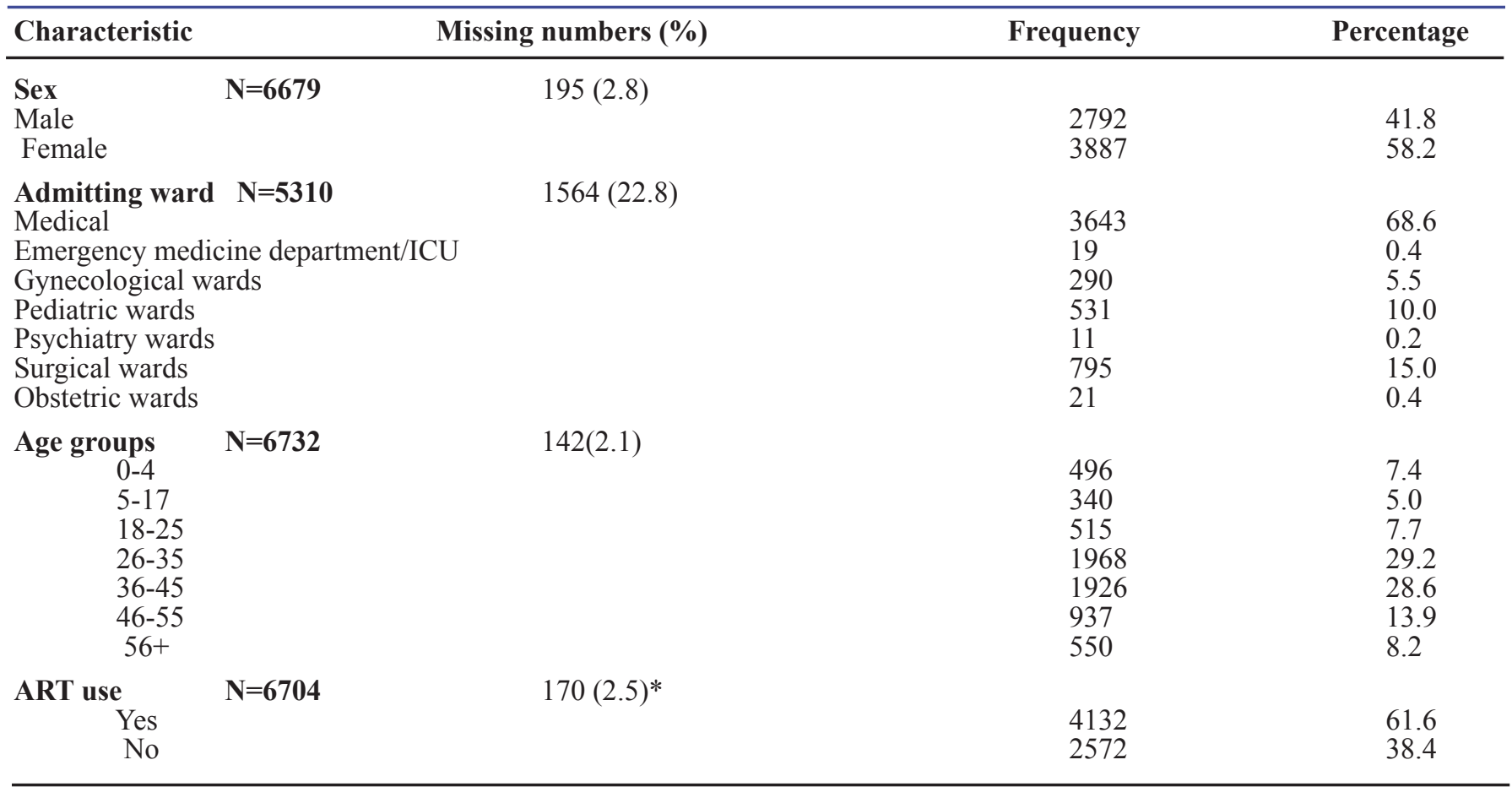

ICU=Intensive Care Unit

*ART status unknown

FIGURE 2: Absolute Number of Admissions from June 2005 to June 2015 Years

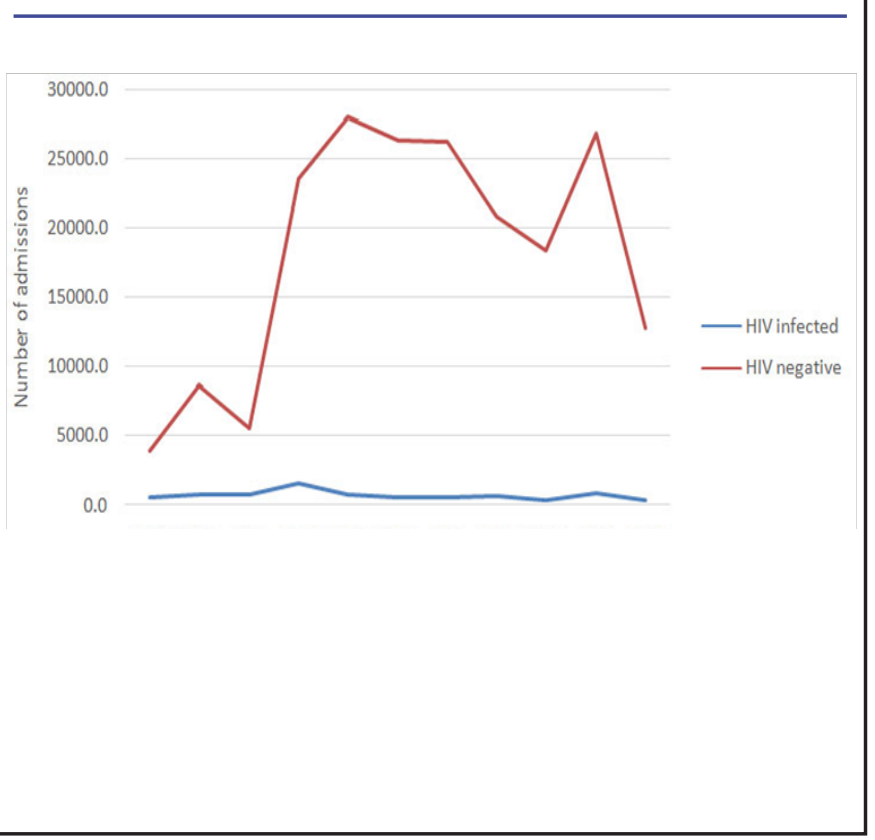

FIGURE 3: Comparison of Hospital Base (MNH) and General HIV Prevalence in the City of Dar es Salaam

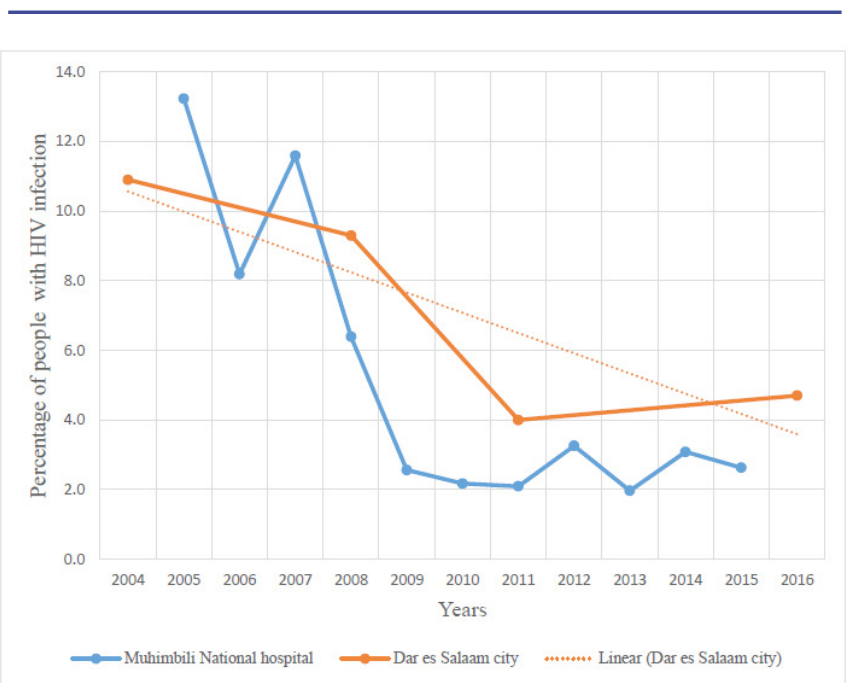




\section{TABLE 2: Causes of Admissions of HIV Infected Patients in Muhimbili National Hospital From June 2005 to June 2015, $\mathrm{N}=6482^{*}$}

\begin{tabular}{llcl}
\hline SN. & Diagnosis & Frequency & Percentage \\
\hline 1. & Tuberculosis of any form & 1396 & 21.5 \\
2. & Anemias & 1016 & 15.6 \\
3. & Cancer & 789 & 12.2 \\
4. & CNS infections & 541 & 8.3 \\
5. & Chronic kidney disease (CKD) & 308 \\
6. & Cardiovascular diseases & 235 \\
7. & Chronic Diarrhea & 231 \\
8. & Chest infections other than Tuberculosis & 218 \\
9. & Other Infections & 206 \\
10. & Malnutrition & 198 \\
11. & Surgical conditions other than cancer & 161 \\
12. & Noninfectious Central nervous system diseases & 159 \\
13. & Encephalopathy from any cause & 155 \\
14. & Oral/Esophageal candidiasis & 118 \\
15. & Psychiatric disorders & 82 \\
16. & Peptic Ulcer Disease & 73 \\
17. & Unspecified diagnosis in HIV & 64 \\
18. & Skin diseases (noninfectious) & 64 \\
19. & Liver diseases (noninfectious) & 49 \\
20. & Septicemia & 47 & 3.6 \\
21. & Others & 372 & 3.4 \\
& & & 3.0 \\
\hline
\end{tabular}

CKD included diagnoses such as CKD, Nephrotic syndrome and HIV associated nephropathy (HIVAN)

Liver diseases included all liver diseases other than viral hepatitis and

malignancies

Genital viral infections included genital herpes and genital warts

$\mathrm{ENT}=$ Ear, Nose and throat

*Only 6482 patients had documented discharge diagnoses

having been mainly secondary to HIV infection itself, HIV drug-induced or treatment failure. A study in Ethiopia found that Zidovudine-based ART and duration on ART predicted anaemia among ART experienced patients while presence of opportunistic infections (tuberculosis being among them) and rural residence predicted presence of anaemia among ART naïve patients. ${ }^{39}$ Anaemia has been found to be an independent risk factor for death among HIV-infected patients ${ }^{40}$ and among HIV/TB co-infected patients. ${ }^{41}$

\section{Limitations}

Due to inadequate documentation, some information from the hard copy files were missing. Files of some patients were nowhere to be seen due to inadequate filing system and record keeping of the paper based files. Since HIV testing was not done to all admitted patients, it is possible that some patients might had been hospitalized with HIV related diseases but were categorised as HIV uninfected, and thus leading to under estimation of proportion of HIV related admissions.

\section{CONCLUSION}

There has been a drastic drop of HIV related admissions at Muhimbili National Hospital from the year 2005 despite the fact that total hospital admissions have been on increase. HIV remains a problem of the adults, largely females. HIV infected patients were more likely to be admitted with medical conditions than others. Severe immunosuppression was prominent among the admissions. Despite the availability of ART and effective anti-tubercular drugs, tuberculosis remained the most common opportunistic infection and a cause of admission. Anaemia and cancers have become more important causes of admission than were diarrhoea and other infections, which had been the most common conditions in the preART era.

Acknowledgements: We acknowledge the board of Muhimbili National Hospital for the intention and determination in investigating the trends of admission of HIV infected patients in the hospital and for entrusting us with the task. We are grateful to study funding support from the Muhimbili University of Health and Allied Sciences. Special thanks to Mr. Mohamed Bakari and to an epidemiologist from MUHAS Dr. Mucho Mizinduko for their guidance in data analysis.

\section{REFERENCES}

1. World Health Organization. Countries Emergencies Global Health Observatory ( GHO ) data HIV / AIDS. Global Health Observatory (GHO) data. Reviewed 2018 Geneva: WHO. www.who.int/gho/ hiv/en/. Accessed 26 May 2020.

2. Kharsany ABM, Karim QA. HIV infection and aids in sub-saharan africa: current status, challenges and opportuniies. Open AIDS J. 2016;10(1):34-48. 
3. Ministry of Health and Social Welfare: The National AIDS Cotrol Program (NACP). HIV/AIDS in Tanzania. 2017 Dar es Salaam: MOHSW. www.nacp.go.tz/about-us/hivaids-in-tanzania. Accessed 15 April 2018.4. Mhalu F, Mbena E, Pallangyo K, et al. Prevalence of HIV infection among selected patients in Tanzania. AIDS. 1987;1:217-21.

5. Mgone CS, Mhalu FS, Shao JF, et al. Prevalence of HIV-1 infection and symptomatology of AIDS in severely malnourished children in Dar es Salaam, Tanzania. J Acquir Immune Defic Sydromes. 1991;4:910-3.

6. TACAIDS. Tanzania HIV / AIDS and malaria indicator survey 2007-2008. TACAIDS, ZAC, NBS,OCGS, and ICF International. 2008.www.google.co.tz/url?sa=t\&rct=j\&q=\&es$\mathrm{rc}=\mathrm{s} \&$ source $=$ web\& $\mathrm{cd}=1 \& \mathrm{ved}=0 \mathrm{CCAQFjAAahUKEw}-$ jdjeztv7DIAhWC1YAKHdAhBBk\&url=http://tacaids. go.tz/index.php?option=com_docman\&task=doc_download\&gid=77\&Itemid $=142 \& \overline{u s g}=$ AFQjCNEJEk8zpG xY1beadsi-Wp8JSQu_g\&sig2=-5wDxrM19pZj. Accessed 15 April 2018

7. Pallangyo K, Hakanson A, Lema L, et al. High HIV seroprevalence and increased HIV-associated mortality among hospitalized patients with deep bacterial infections in Dar-es-Salaam, Tanzania. AIDS Public Policy J. 1992;6:796-971.

8. Archibald LK, Den Dulk MO, Pallangyo KJ, Barth Reller L. Fatal Mycobacterium tuberculosis bloodstream infections in febrile hospitalized adults in Dar es Salaam, Tanzania. Clin Infect Dis. 1998;26(2):290-6.

9. Mkony C, Kwesigabo G, Lyamuya E, Mhalu F. Prevalence and clinical presentation of HIV infection among newly hospitalized surgical patients at Muhimbili National Hospital, Dar es Salaam, Tanzania. East Afr Med J. 2003;80(12):640-5.

10. Van Cleeff M, Chum H. The proportion of tuberculosis cases in Tanzania attributable to human immunodeficiency virus . Int J epidemiol. 1995;24(3):637-42.

11. WHO. Global Tuberculosis Control 2011. Geneva http://apps. who.int/iris/bitstream/10665/44728/1/9789241564380 eng.pdf. Accessed 15 April 2018.

12. Lawn SD, Bekker L, Middelkoop K, Myer L, Wood R. Impact of HIV infection on the epidemiology of tuberculosis in a peri-urban community in South Africa: The need for age-specific interventions. HIV/AIDS. 2006;42(April):1040-7.

13. Gulick RM, Mellors JW, Havlir D, et al. Treatment with indinavir, zidovudine, and lamivudine in adults with human immunodeficiency virus infection and prior antiretroviral therapy. N Engl J Med. 1997;337:734-9.

14. Henkel J. Attacking AIDS with a ' Cocktail ' Therapy. US Food and drug administarationration . 1999. www.fda.gov/FDAC/features/1999/499_AIDS.html. Accessed 15 May 2020.

15. Palella F, Delaney K, Moorman A, et al. Declining morbidity and mortality among patients with advance human immunodeficiency virus infection. N Engl J Med. 1998;338(13):853-60.

16. Mocroft A, Ledergerber B, Katlama C, et al. Decline in the AIDS and death rates in the EuroSIDA study : an observational study . Lancet. 2003;362(9377):22-9.

17. Murphy E, Collier A, Kalish L, et al. Highly active antiretroviral therapy decreases mortality and morbidity in patients with advanced HIV disease. Ann Intern Med. 2001;135(1):17-26.

18. Wong CS, Lo FA, Cavailler P, et al. Causes of death in hospitalised HIVinfected patients at a national referral centre in Singapore: a retrospective review from 2008 to 2010. Ann Acad Med Singapore. 2012;41(12):571-6.

19. The Antiretroviral Therapy Cohort Collaboration. Causes of Death in HIV1 infected patients treated with antiretroviral therapy, 1996-2006: collaborative analysis of 13 HIV cohort studies. Clin Infect Dis. 2010;50(10):1387-96.

20. TACAIDS, NBS, ORC Macro. Tanzania HIV/AIDS Indicator Survey 2003-4. Calverton, Maryland, USA: TACAIDS, NBS \& ORC Calverton, Maryland USA: 2005. http://scholar.google. com/scholar?hl=en\&btnG=Search\&q=intitle:Tanzania + HIV $/$ AIDS+Indicator+Survey+2003\#1 Accessed 10 August 2018.

21. Tanzania National Bureau of Statistics (NBS). Tanzania HIV/
AIDS and malaria indicator survey 2011-12. Dar es Salaam: 2013. http://www.tacaids.go.tz/index.php?option=com content\&view=article\&id=139:current-status-of-hiv-and-aids\&catid $=31$ \&Itemid $=159$ Accessed 10 August 2018 .

22. Tanzania Minisrty of Health, Community Development, Gender, Elderly and Children. Tanzania HIV impact survey (THIS) 2016/2017. Dar es Salaam: 2017.http:/www.nbs.go.tz/nbs/ takwimu/this2016-17/Tanzania_SummarySheet_English.pdf Accessed 10 August 2018.

23. Kumar A, Kilaru KR, Forde S, Roach TC. Changing HIV infection related mortality rate and causes of death among persons with HIV infection before and after the introduction of highly active antiretroviral therapy analysis of all HIV related deaths.J Int Assoc Physicians AIDS Care (Chic). 2006;5(3):109-14.

24. Solomon SS, Kumarasamy N, Celentano DD, Yepthomi TH, Arvind VP, Solomon S. Trends in HIV-related morbidity among patients admitted to a South Indian tertiary hospital between 1997 and 2003. AIDS Care 2006;18(4):366-70.

25. United Republic of Tanzania. Tanzania in Figures. National Bureau of Statistics, 2016 Dar es Salaam, Tanzania.www.nbs.go.tz Accessed 10 August 2018.

26. National Bureau of Statistics. 2002 Census Population Distribution as per 2012 Population Census Administrative Units. http:// www.nbs.go.tz/nbs/takwimu/census2012/Pop_dist_by_enu_me_ area as per 2002 pop and housing census.pdf Âccessed 10 August $201 \overline{8}$.

27. Uganda AIDS Commission. Uganda population based HIV impact assessment 2017. https://reliefweb.int/sites/reliefweb.int/ files/resources/UPHIA Uganda factsheet.pdf Accessed 14 May 2020. p 62-5

28. Kimanga DO, Ogola S, Umuro M, et al. Prevalence and incidence of HIV infection, trends, and risk factors among persons aged 15-64 years in Kenya. JAIDS. 2014;66(Suppl 1):S13-26.

29. Whitworth JAG, Mahe C, Mbulaiteye SM, et al. HIV-1 epidemic trends in rural south-west Uganda over a 10 -year period. Trop Med Int Heal. 2002;7(12):1047-52.

30. Whalen CC, Nsubuga P, Okwera A, Johnson JL. Impact of pulmonary tuberculosis on survival of HIV-infected adults: a prospective epidemiology. AIDS. 2000;14(9):1219-28.

31. Nunn PP, Elliott AM, Mcadam KPWJ. Impact of human immunodeficiency virus tuberculosis in developing countries. Thorax. 1994:49:511-8

32. Siika AM, Ayuo PO, Mwangij AW, et al. Admission characteristics, diagnoses and outcomes of HIV-infected patients registered in an ambulatory HIV care programme in western Kenya. East Afr Med J. 2008;85(11):523-8.

33. Rubaihayo J, Tumwesigye NM, Konde-Lule J, Wamani H, Nakku-Joloba E, Makumbi F. Frequency and distribution patterns of opportunistic infections associated with HIV/AIDS in Uganda. BMC Res Notes. 2016;9(1):501.

34. Cheung MC, Pantanowitz L, Dezube BJ. AIDS related malignancies : emerging challenges in the era of highly active antiretroviral therapy. Oncologist. 2005;10:412-26.

35. WHO. Global Tuberculosis Report 2014. Geneva, Switzerland. http://apps.who.int/iris/bitstre am/10665/137094/1/9789241564809_eng.pdf?ua=1 Accessed 10 August 2017.

36. Datiko DG, Yassin MA, Chekol LT, Kabeto LE, Lindtjørn B. The rate of TB-HIV co-infection depends on the prevalence of infection in a community. BMC Public Health. 2008;30 July;8:266. doi: $10.1186 / 1471-2458-8-266$

37. Ghate M, Deshpande S, Tripathy S, et al. Incidence of common opportunistic infections in HIV-infected individuals in Pune, India : analysis by stages of immunosuppression represented by CD4 counts. Int J Infect Dis. 2009;13(1-8).

38. Moges NA. Prevalence of opportunistic infections and associated factors among HIV positive patients taking antiretroviral therapy in DebreMarkos referral hospital, Northwest Ethiopia. J AIDS Clin Res. 2014;05(05).

39. Gedefaw L, Yemane T, Sahlemariam Z, Yilma D. Anemia and risk factors in HAART naive and HAART experienced HIV positive 
persons in South West Ethiopia : acomparative study. PLoS One. 2013;8(8):e72202.

40. Moore RD, Keruly JC, Chisson RE. Anemia and survival in HIV infection. J Acquir Immune Defic Syndr Hum Retrovirology. 1998;19:29-33.

41. Mugusi FM, Mehta S, Villamor E, et al. Factors associated with mortality in HIV-infected and uninfected patients with pulmonary tuberculosis. BMC Public Health. 2009;9:409.

\section{Peer Reviewed}

Funding: This study was funded by the Muhimbili University of Health and Allied Sciences (MUHAS).

Received: $4^{\text {th }}$ July $2019 \quad$ Accepted: $20^{\text {th }}$ May 2020

Cite this article as: Shayo GA, Nagu T, Msele L, Munseri P, Mbekenga C, Kibusi S, Pallangyo K, Mugusi F. Trends in Hospitalisation for Human Immunodeficiency Virus in a Tertiary Hospital in Dar es Salaam, Tanzania: A Case study.East Afr Health Res J. 2020;4(1):101107. https://doi.org/10.24248/eahrj.v4i1.627

CShayo et al. This is an open-access article distributed under the terms of the Creative Commons Attribution License, which permits unrestricted use, distribution, and reproduction in any medium, provided the original author and source are properly cited. To view a copy of the license, visit http://creativecommons.org/licenses/by/4.0/. When linking to this article, please use the following permanent link: https://doi. org/10.24248/eahrj.v4i1.627 